\title{
Cenplesto
}

\section{A valorização simbólica da leitura no Plano Nacional do Livro e Leitura: uma análise}

\author{
Fabíola Ribeiro Farias \\ Doutoranda; Universidade Federal de Minas Gerais, Belo Horizonte, MG, Brasil; \\ f abirfarias@yahoo.com.br
}

\begin{abstract}
Resumo: Apresentam-se e discutem-se as proposições do Plano Nacional do Livro e Leitura - PNLL para a valorização da leitura como um bem cultural, em seu eixo de ação número três, intitulado "Valorização institucional da leitura e incremento de seu valor simbólico", à luz do conceito de "violência simbólica", de Pierre Bourdieu. Conclui-se que é necessário que a concepção da leitura e, naturalmente, do seu valor simbólico no âmbito do PNLL sejam constantemente discutidos e ressignificados, uma vez que esse entendimento norteará muitas das ações do Plano.
\end{abstract}

Palavras-chave: Leitura. Valor simbólico. Políticas públicas. PNLL.

\section{Introdução}

Em um dos capítulos finais de Infância, um de seus romances memorialísticos, Graciliano Ramos narra o episódio em que seu pai o inicia na leitura dos livros. Após o café, o homem, que nunca se dirigia a ele, mandou que o menino buscasse um livro que estava na cabeceira da cama. Espantada, a criança, que aos nove anos não sabia ler direito e invejava a vida organizada de seus vizinhos, que "[...] andavam limpos, riam alto, frequentavam escola decente e possuíam máquinas que rodavam na calçada como trens.” (RAMOS, 1986, p. 199), recebeu a ordem para que se sentasse e abrisse o volume. Por determinação do pai, leu aos tropeços, mastigando as palavras, mas interessado na família e nos lobos da história lida e mais ainda na atenção paterna a ele dispensada. Na terceira noite, porém, o pai, com um gesto carrancudo e sem explicação, afastou-o rispidamente e interrompeu as sessões de leitura. Decepcionado, mas com a mágoa já confortada, o menino procura a ajuda da prima Emília, que sugere que ele leia o livro sozinho. Mas, em conformidade 
com a opinião de sua mãe, que o considerava uma besta, o menino não se sente capaz da tarefa. Diz o menino:

Emília combateu a minha conviç̧ão, falou-me dos astrônomos, indivíduos que liam no céu, percebiam tudo quanto há no céu. Não no céu onde moram Deus Nosso Senhor e a Virgem Maria. Esse ninguém tinha visto. Mas o outro, o que fica por baixo, o do Sol, da Lua e das estrelas, os astrônomos conheciam perfeitamente. Ora, se eles enxergavam coisas tão distantes, porque [sic] não conseguiria eu adivinhar a página aberta diante dos meus olhos? Não distinguia as letras? Não sabia reuni-las e formar palavras? (RAMOS, 1986, p. 203).

Graciliano Ramos nos relata uma experiência. Pela palavra, a escrita e a lida, o autor recria e reinventa a experiência da leitura, o afeto do pai e a descoberta de um mundo imenso. E, sabendo o que faz, nos oferece uma metáfora para pensar e significar o ato de ler.

Compreender a leitura e a escrita, para além das habilidades de ler e escrever, é tarefa complexa e ponto de partida para a construção de uma política pública para a área, pois será esse entendimento que sustentará suas diretrizes, estratégias e ações.

Este artigo tem como objetivo identificar e discutir as proposições do Plano Nacional do Livro e Leitura para a valorização da leitura como um bem cultural, em seu eixo de ação número 3, intitulado "Valorização institucional da leitura e incremento de seu valor simbólico".

Para isso, faremos uma apresentação do Plano Nacional do Livro e Leitura, considerando o processo de sua elaboração, seus princípios norteadores, seus pressupostos e eixos de ação. Em seguida, discutiremos a construção do valor simbólico, a partir do entendimento de Antonio Gramsci sobre a formação do senso-comum (COUTINHO, 2011) e do conceito de poder simbólico de Pierre Bourdieu (BOURDIEU, 2010). Para refletir sobre a construção de valor para a leitura, trabalharemos também com a perspectiva de consciência, conforme a abordagem de Theodor Adorno (ADORNO, 1995). À luz desses conceitos, faremos a análise do eixo de ação número 3, intitulado "Valorização institucional da leitura e incremento de seu valor simbólico", do Plano Nacional do Livro e Leitura e apresentaremos nossas considerações finais. 
É importante ressaltar que a reflexão sobre documentos que norteiam a elaboração de políticas públicas para a participação na cultura escrita no país tem sido objeto de reflexão em nossa trajetória acadêmica e profissional, especialmente o desvelamento das visões de mundo que emergem desses documentos, muitas vezes despercebidas pelo uso contínuo e acrítico de termos e ideias aparentemente consolidados, mas quase sempre evidentes numa análise atenta dos discursos.

\section{O Plano Nacional do Livro e Leitura (PNLL)}

O Plano Nacional do Livro e Leitura (PNLL), elaborado coletivamente por representantes do poder público das três esferas governamentais e da sociedade civil em seminários, reuniões, audiências e conferências foi instituído por meio da Portaria Interministerial $\mathrm{n}^{\circ}$ 1442, de 10 de agosto de 2006 pelos ministérios da Cultura e da Educação e, posteriormente, pelo Decreto Presidencial n ${ }^{\circ} 7559$, de 01 de setembro de 2011.

Em seu texto introdutório, o PNLL apresenta suas ambições e desafios:

Pretende-se conferir a este Plano a dimensão de uma Política de Estado, de natureza abrangente, que possa nortear, de forma orgânica, políticas, programas, projetos e ações continuadas desenvolvidos no âmbito de ministérios - em particular os da Cultura e da Educação -, governos estaduais e municipais, empresas públicas e privadas, organizações da sociedade e de voluntários em geral, procurando evitar o caráter por demais assistemático, fragmentário e pulverizado com que se têm implementado essas iniciativas em nosso país, desde, pelo menos, o início do século XIX. (BRASIL, 2010, p. 21).

O Plano se pauta pela democratização do acesso à leitura e ao livro em todo o país e se justifica em três preocupações. A primeira delas se refere ao insatisfatório desempenho de leitura dos brasileiros, apontado pelos resultados de distintos instrumentos de avaliação: Mapa do Alfabetismo no Brasil (Instituto Nacional de Estudos e Pesquisas Educacionais Anísio Teixeira - Inep / MEC, 2003), Pesquisa Nacional por Amostra de Domicílios - PNAD (2009, IBGE), Indicador Nacional do Alfabetismo Funcional - INAF (Instituto Paulo Montenegro, 2001, 2005 e 2009), Programa Internacional de Avaliação de Estudantes - PISA (2000 e 2006), Sistema Nacional de Avaliação da Educação 
Básica - SAEB (2001, 2003 e 2006), Retratos da Leitura no Brasil 2001 (Câmara Brasileira do Livro, Sindicato Nacional de Editores e Livreiros / Abrelivros) e 2007 (Instituto Pró-Livro) e Censo Nacional de Bibliotecas Públicas Municipais (Ministério da Cultura / Fundação Getúlio Vargas, 2009), conforme aponta o PNLL (BRASIL, 2010, p. 25). A segunda lacuna diz respeito ao acesso restrito dos brasileiros a livros e outros materiais de leitura, conforme constatado por distintas edições da pesquisa Retratos da leitura no Brasil, realizada por entidades ligadas à edição e comércio de livros no país: "Um aspecto capital apontado pela pesquisa é o de que o brasileiro lê em média 1,8 livro por ano, índice muito baixo se comparado a outros países.” (BRASIL, 2010, p. 28) A terceira questão apontada como problema para a formação de leitores no Brasil é o pouco ou nenhum acesso a bens culturais de qualquer natureza.

Como orientações conceituais, o PNLL consigna seus princípios norteadores, entendidos como

[...] alguns pressupostos básicos sobre os quais se assenta o Plano, uma vez que correspondem a uma tomada de posição conceitual em relação à leitura e ao livro e, particularmente, traduzem o horizonte das muitas contribuições absorvidas pelo Plano no amplo fórum que se instaurou para a discussão do tema [...] (BRASIL, 2010, p. 31).

Apresentados em tópicos, os referidos pressupostos contemplam diretrizes quantitativas e qualitativas da UNESCO, traduzidas na presença do livro e em sua valorização simbólica no imaginário da população, incluindo o exemplo das famílias para as crianças, e o compromisso das escolas com a formação de leitores. Pelo aspecto quantitativo, estão considerados o acesso ao livro, especialmente pela existência de bibliotecas e livrarias, e a comercialização dos mesmos com preços baixos e acessíveis para a população. Além disso, é ressaltada a preocupação com a competência em informação, que, para a UNESCO,

[...] encontra-se no cerne do aprendizado ao longo da vida, constituindo direito humano básico em um mundo digital, necessário para promover o desenvolvimento, a prosperidade e a liberdade - no âmbito individual e coletivo - e para criar condições plenas de inclusão social. (BRASIL, 2010, p. 31). 
Os pressupostos postulam a compreensão da leitura como uma prática social e cultural, de construção de sentidos, que traz em si a multiplicidade de visões de mundo e de interpretações em contextos distintos, além de contemplar a diversidade dos povos e o intercâmbio entre diferentes culturas. Extrapolando a abordagem educacional e a busca pelas habilidades de ler e escrever, a leitura e o livro, para o PNLL, se inserem em uma perspectiva cultural ampla, trabalhada em três dimensões pelo Ministério da Cultura: valor simbólico, direito de cidadania e economia, sem preponderância de um recorte sobre os outros, mas com mais foco nos dois primeiros.

Apesar da centralidade da palavra escrita, estão consideradas nesse contexto outras linguagens e códigos, como as tradições orais e as novas textualidades que surgem com o advento das tecnologias digitais. Aliás, os novos formatos e suportes de livros e texto, especialmente os eletrônicos, precisam, de acordo com os pressupostos do PNLL, ser considerados em sua complexidade, tanto no que diz respeito ao acesso quanto às questões relativas aos direitos autorais, que se alteram muito nesse novo contexto.

A biblioteca, por sua vez, é concebida como um centro produtor e difusor de informação e cultura, com atividades de lazer e entretenimento, que estimulem a criação e a fruição de diversos bens artísticos e culturais, "[...] promovendo a interação máxima entre os livros e esse universo que seduz as atuais gerações" (BRASIL, 2010, p. 33).

O PNLL recomenda atenção especial à leitura literária, por entender que ela contribui de maneira significativa para a formação vertical do leitor, nas três funções estabelecidas pelo crítico Antonio Candido:

a) a capacidade que a literatura tem de atender à nossa imensa necessidade de ficção e fantasia; b) sua natureza essencialmente formativa, que afeta o consciente e o inconsciente dos leitores de maneira bastante complexa e dialética, como a própria vida, em oposição ao caráter pedagógico e doutrinador de outros textos; c) seu potencial de oferecer ao leitor um conhecimento profundo do mundo, tal como faz, por outro caminho, a ciência. (BRASIL, 2010, p. 33).

Também é pressuposto do PNLL o atendimento a pessoas e grupos que necessitem de atenção especializada, como jovens e adultos que não foram, por 
motivos diversos, alfabetizados na idade certa de acordo com os padrões estabelecidos no país, ou pessoas com deficiências ou transtornos globais de desenvolvimento.

A produção e distribuição de materiais, em suportes distintos e com temas diversificados, chamados pelo PNLL de "meios educativos", para toda a comunidade escolar são consideradas importantes para a garantia do acesso a bens culturais.

Além da atuação específica junto à comunidade escolar, o PNLL considera fundamental a observância do acúmulo de discussões, pesquisas acadêmicas e relatos de experiências sobre a promoção da leitura na elaboração de políticas públicas para a área nas três esferas governamentais, especialmente na formulação dos planos municipais e estaduais de leitura. A elaboração destes deve ser estimulada para que os programas de promoção da leitura possam ter organicidade, com projetos de curto, médio e longo prazos. Muito importante, a integração entre os ministérios da Cultura e da Educação, principalmente, e com outros ministérios, é considerada fundamental para o desenvolvimento de uma política pública para o livro e a leitura. O PNLL se integra ao Plano Nacional de Cultura e ao Plano de Desenvolvimento da Educação.

O PNLL dispõe também, no âmbito dos seus pressupostos, sobre seu compromisso com as cadeias criativa e produtiva do livro, destacando a importância do fomento ao setor livreiro e tendo em vista a produção de livros com diversidade e grandes tiragens, de maneira a garantir bons preços para a população.

Por fim, o documento aponta a necessidade de avaliações contínuas das metas, programas e ações desenvolvidos, bem como de seus resultados, tendo em vista as adequações necessárias para sua melhoria.

O PNLL tem caráter de recomendação e oferece as diretrizes para as ações em prol da democratização do acesso e da valorização da leitura no país, através de quatro eixos:

1. Democratização do acesso;

2. Fomento à leitura e à formação de mediadores; 
3. Valorização institucional da leitura e incremento de seu valor simbólico;

4. Desenvolvimento da economia do livro.

No primeiro eixo são elencados pontos atinentes à promoção do acesso da população a livros e outros materiais de leitura, como o próprio título já indica, a saber: implantação de novas bibliotecas; fortalecimento da rede atual de bibliotecas; conquista de novos espaços de leitura; distribuição de livros gratuitos; melhoria do acesso ao livro e a outras formas de expressão da leitura; incorporação e uso de tecnologias de informação e comunicação.

O segundo eixo contempla ações para o fomento à leitura e a formação de mediadores, desdobrando-se nos seguintes tópicos: formação de mediadores de leitura; projetos sociais de leitura; estudos e fomento à pesquisa nas áreas do livro e da leitura; sistemas de informação nas áreas de bibliotecas, da bibliografia e do mercado editorial; prêmios e reconhecimento às ações de incentivo e fomento às práticas sociais de leitura.

No terceiro eixo são apontadas as formas para a valorização institucional da leitura e incremento do seu valor simbólico: ações para converter o fomento às práticas sociais da leitura em Política de Estado; ações para criar consciência sobre o valor social do livro e da leitura; publicações impressas e outras mídias dedicadas à valorização do livro e da leitura.

O quarto eixo, que dispõe sobre o desenvolvimento da cadeia produtiva do livro, apresenta as seguintes propostas: desenvolvimento da cadeia produtiva do livro; fomento à distribuição, circulação e consumo de bens de leitura; apoio à cadeia criativa do livro; maior presença no exterior da produção nacional literária, científica e cultural editada.

\section{A construção de valor simbólico}

O relato do escritor Graciliano Ramos sobre sua primeira aproximação com a leitura e os livros, parte do romance memorialístico Infância, nos mostra uma experiência mediada pela autoridade e pelo afeto do pai. É ele, o pai, quem autoriza e ensina a leitura. E é o mesmo pai que, num segundo momento, abandona a tarefa de ensinar o menino a ler. Mas a dor do abandono não tira da 
criança o que a ela foi dado no primeiro tempo: a descoberta das letras, o desejo de conhecer histórias, de saber dos lobos e do mundo imenso que, já entendia ela, estava encerrado nos livros. Mesmo diante das dificuldades, aquele menino se aventurou no desvendamento das letras.

Talvez seja essa relação, a que desperta e legitima o interesse pela leitura, a que esteja contemplada na intenção do eixo 3: "Valorização institucional da leitura e incremento do seu valor simbólico" do PNLL.

A valorização institucional de algo passa, necessariamente, pela construção de valor simbólico do que se pretende valorizar. O mesmo ocorre ao seu incremento, pois para que algo seja incrementado, melhorado, é necessária a compreensão de um valor já instituído.

A leitura, os livros e a literatura vêm se constituindo, ao longo das duas últimas décadas, em um discurso constante entre educadores, professores, bibliotecários, escritores, editores, gestores públicos, agentes comunitários e mediadores de leitura, estes últimos como um produto do contexto gerado por essa grande mobilização ${ }^{1}$. Apesar do constante anúncio da escassez da leitura, apontada pelas muitas pesquisas sobre o tema no Brasil, podemos verificar a existência, cada vez maior e mais descentralizada em relação ao eixo Rio de Janeiro - São Paulo e às capitais brasileiras, de festivais e feiras literárias, bienais do livro, oficinas de escrita criativa, circuitos de encontros com escritores, concursos literários, seminários, programas públicos e privados de distribuição gratuita de livros e muitas outras atividades que têm a leitura, o livro e a literatura como objeto. O mercado editorial brasileiro aponta na mesma direção, com uma produção anual em 2015 de 52.427 títulos editados, que somam 446.848.571 exemplares produzidos e 389.274.495 livros vendidos no mesmo $a^{2}{ }^{2}$. A grande repercussão e adesão ao Plano Nacional do Livro e Leitura e o estímulo por ele oferecido e aceito por instituições públicas e pela sociedade civil em todo o país são uma resposta clara a essa movimentação, conforme demonstra a mobilização de estados e municípios em torno da elaboração dos planos municipais e estaduais de leitura ${ }^{3}$.

Entretanto, como todo assunto que ganha as ruas e o interesse da população, a leitura, os livros e a literatura, bem como os temas a eles atinentes, 
como a valorização simbólica e a construção de políticas públicas, por exemplo, passam a fazer parte do duro chão do senso-comum. E se isso representa um ganho em termos de participação social, uma vez que permite a todos, sem exceção, a expressão de opiniões e entendimentos sobre o tema, por outro pode trazer em si um esvaziamento da discussão, marcado pela ausência de experiência, de repertório teórico e de reflexão para tal, necessários a construções políticas consistentes para a área.

Para Gramsci, o senso-comum é "“[...] a concepção do mundo absorvida acriticamente pelos vários ambientes sociais e culturais nos quais se desenvolve a individualidade moral do homem médio." (COUTINHO, 2011, p. 148). Dito de outra maneira, aderir ao senso-comum, principalmente sem o saber, significa a aceitação e a repetição de um entendimento das coisas sem qualquer reflexão ou questionamento sobre as mesmas: uma ideia é recebida por alguém, que a repete, validando-a e fazendo dela uma verdade pronta em seu grupo social.

Os discursos sobre a leitura se realizam, em grande medida, nessa perspectiva. Em um bloco que associa a leitura ao prazer, vemos com frequência frases como "ler é uma viagem", "a leitura é uma diversão", "leia um livro e dê asas à sua imaginação", "leia e conheça a magia / o mundo encantado dos livros" etc. Há também as afirmações relativas ao aspecto utilitário da leitura: "quem lê sabe mais", "leia mais para escrever melhor", "quem lê tem mais oportunidades de trabalho" etc.

É importante ressaltar que essas proposições não são de todo sem pertinência. Mas é necessário discuti-las e ao seu contexto de produção, colocálas em suspensão, para que possamos entender de que maneira elas foram estabelecidas e por que se firmaram como "verdades" em seu contexto.

Um dos principais e mais efetivos instrumentos de criação, de conhecimento e de construção simbólica do mundo é a língua, a comunicação. Por meio da língua, tanto na fala quanto na escrita, criamos entendimentos e valoração para a vida, para as nossas questões e interesses. Segundo Bourdieu (2010), os sistemas simbólicos exercem um poder estruturante, isto é, uma potência de organização e significação imediata do mundo. Mas um sistema simbólico não é, por si só, um poder simbólico. Para que um sistema simbólico 
se constitua um poder simbólico é necessário que se estabeleça uma relação entre os que exercem o poder e os que a ele estão submetidos, numa dinâmica de produção social da crença. Uma das condições para que essa relação se estabeleça é que ela não seja explícita, que não se mostre como uma relação de dominação simbólica:

O poder simbólico como poder de constituir o dado pela enunciação, de fazer ver e fazer crer, de confirmar ou de transformar a visão do mundo e, deste modo, a acção [SIC] sobre o mundo, portanto o mundo; poder quase mágico que permite obter $\mathrm{o}$ equivalente daquilo que é obtido pela força (física ou econômica), graças ao efeito específico de mobilização, só se exerce se for reconhecido, quer dizer, ignorado como arbitrário. (BOURDIEU, 2010, p. 14).

Assim, a relação de dominação, de imposição de uma visão de mundo de um grupo sobre o outro não pode ser exposta como tal, mas deve ser apresentada sob a aparência de normalidade, de algo no curso da ordem natural das coisas. Os dominados, sem se saberem nessa condição, precisam ser constantemente convencidos dos sistemas simbólicos impostos, para que o status quo não seja sequer questionado.

A definição de uma ordem social de acordo com os interesses de cada grupo é disputada simbolicamente, seja na vida cotidiana, seja na voz de instituições e especialistas que possuem prestígio e um lugar privilegiado de enunciação no estabelecimento de ordens e valores sociais. Dito de outra maneira, os discursos de autoridades, individuais, mesmo que a serviço dos interesses do seu grupo, ou institucionais são um poder simbólico, validado pela relação de força entre os que estão investidos do saber e os que o aceitam como tal.

A imposição escamoteada de uma visão de mundo, de valores que ordenam socialmente a vida, garantindo a alguns o lugar de dominação e submetendo muitos à posição de dominados é denominada por Bourdieu de violência simbólica.

É enquanto instrumentos estruturados e estruturantes de comunicação e de conhecimento que os "sistemas simbólicos" cumprem a sua função política de instrumentos de imposição ou de legitimação da dominação, que contribuem para assegurar a dominação de uma classe sobre outra (violência simbólica) dando o 
reforço da sua própria força às relações de for que as fundamentam e contribuindo assim, segundo a expressão de Weber, para a "domesticação dos dominados." (BOURDIEU, 2010, p. 11).

Tendo isso em vista, veremos de que maneira o PNLL constrói suas estratégias para a valorização simbólica da leitura.

\subsection{O valor da leitura}

A leitura, considerada como um bem cultural, insere-se, como outros bens culturais, em um movimento para a produção de crença em seu valor, isto é, para a produção do seu valor simbólico. Para além de um produto, de um ato, ela se inscreve em um lugar de prestígio, diferindo-se de um produto ou hábito qualquer. A construção desse prestígio se dá de maneira velada, como se natural fosse, nas relações entre agentes e instituições no campo, que validam e legitimam, em uma escala que extrapola o próprio campo, seu valor simbólico. Dito de outra maneira, o que caracteriza e valoriza a leitura como um bem cultural é o fato de ela ser "[...] um produto como os outros, mas com uma crença, que ela própria deve ser produzida." (BOURDIEU; CHARTIER, 2011, p. 240) A produção dessa crença é, para Bourdieu, “[...] um dos únicos pontos sobre os quais a política cultural pode agir [...]" (BOURDIEU; CHARTIER, 2011, p. 240), reforçando a produção da crença. É a esse ponto que se dedica o eixo de número 3, intitulado "Valorização institucional da leitura e incremento de seu valor simbólico", do Plano Nacional do Livro e Leitura.

Quando atribuímos à leitura um lugar de prazer, de viagens, de magia e de fantasia não fazemos uma analogia falsa, mas sim parcial e, principalmente, superficial. Parcial porque lidamos apenas com uma das muitas perspectivas da leitura, que, é preciso destacar, nem sempre se realiza, pois nem todos encontrarão prazer, farão viagens ou terão uma experiência mágica ao ler um livro, ainda que de literatura - nos livros informativos ou técnicos, cujos conteúdos também acessamos via leitura, o prazer anunciado acima nos parece mais improvável. Superficial porque faz parecer que ler é apenas uma escolha que não depende de condições objetivas para sua aprendizagem e prática. 
A aprendizagem da leitura é um longo e trabalhoso processo, que exige de quem ensina e de quem aprende muita dedicação, tempo e investimento na tarefa. Para além da técnica de decifração e junção de letras e sílabas, da apropriação lenta e gradual do processo de escrita e da construção de sentidos, tarefa para toda a vida, a participação na cultura escrita implica, especialmente, o entendimento do que significa ler e escrever. Exige a compreensão da leitura e da escrita como práticas sociais investidas de poder, inseridas na história e determinadas, em grande medida, por condições materiais. Em outras palavras, o ensino e a aprendizagem da escrita pressupõem, em níveis diferentes para quem ensina e para quem aprende, a mesma consciência postulada por Adorno (1995) para a educação, isto é, a capacidade de pensar o seu objeto em relação com o mundo e consigo mesmo:

\begin{abstract}
Mas aquilo que caracteriza propriamente a consciência é o pensar em relação à realidade, ao conteúdo - a relação entre as formas e estruturas de pensamento do sujeito e aquilo que este não é. Este sentido mais profundo de consciência ou faculdade de pensar não é apenas o desenvolvimento lógico formal, mas ele corresponde literalmente à capacidade de fazer experiências. Eu diria que pensar é o mesmo que fazer experiências intelectuais. (ADORNO, 1995, p. $151)$.
\end{abstract}

Os argumentos mais comuns e recorrentes que podemos perceber nos discursos sobre a leitura, mesmo entre um número significativo de professores, bibliotecários e mediadores de leitura, refletem a ausência da reflexão apontada por Adorno (1995), denominada pensamento reificado, que absorve o status quo e o repete à exaustão, fazendo dele uma verdade inquestionável. Em seminários sobre o tema, publicações em redes sociais, encontros e oficinas com profissionais que trabalham na área, as justificativas para a valorização da leitura se sustentam, com muita frequência, nos argumentos apresentados acima, muito especialmente no prazer, tornando-o um discurso legítimo - e reificado sobre a leitura.

Não é tarefa deste artigo fazer uma abordagem sobre a função da leitura e sobre sua importância, mas sim problematizar a construção de valores simbólicos para tal. Assim, pretendemos discutir as bases nas quais os referidos valores são construídos, a partir da reflexão teórica sobre senso-comum 
(Gramsci), poder simbólico (Bourdieu) e consciência (Adorno), apresentada acima, além de autores que se dedicaram especificamente a essa discussão no campo da leitura, tendo como objeto de análise os pressupostos conceituais apresentados no texto do PNLL e as ações estabelecidas no eixo 3: "Valorização institucional da leitura e incremento de seu valor simbólico" do mesmo.

\section{Pressupostos e estratégias do PNLL para a valorização simbólica da leitura}

Dentre os princípios norteadores e pressupostos apontados pelo PNLL como uma tomada de posição conceitual, podemos destacar três pontos que estão diretamente vinculados à preocupação com o incremento simbólico da leitura. Os dois primeiros estão entre as recomendações da UNESCO e se referem ao lugar de destaque que o livro deve ocupar no imaginário nacional e ao exemplo e influência que as famílias devem exercer sobre suas novas gerações, por meio do compartilhamento de práticas de leitura. O terceiro se insere como diretriz de uma perspectiva sistêmica da ação do Ministério da Cultura, que destaca a cultura (e a leitura, como desdobramento) como valor simbólico como uma de suas três dimensões (as outras duas são a cultura como direito de cidadania e a cultura como economia).

Conforme destacado anteriormente, o eixo 3 do PNLL tem como título "Valorização institucional da leitura e incremento de seu valor simbólico" e dispõe sobre estratégias e ações com esse objetivo. Dividido em três itens, o eixo 3 se organiza em torno de "ações para converter o fomento às práticas sociais da leitura em Política de Estado", "ações para criar consciência sobre o valor social do livro e da leitura" e "publicações impressas e outras mídias dedicadas à valorização do livro e da leitura".

Nas "ações para converter o fomento às práticas sociais da leitura em Política de Estado", foram elencados alguns pontos, como a criação e o fortalecimento de programas governamentais de fomento à leitura, a exemplo do Colegiado Setorial do Livro, Leitura e Literatura (CSLLL) e o Programa Nacional de Incentivo à Leitura (PROLER); a formulação dos planos estaduais e municipais de Livro e Leitura, acarretando a formulação de políticas setoriais 
nacional, estaduais e municipais; a realização de eventos (fóruns, congressos, seminários) em torno da agenda do livro e leitura; as pesquisas sobre políticas públicas para o livro, leitura e biblioteca pública; estruturação da área de formulação, coordenação e execução da política setorial; criação de fundos e agências para financiamento e fomento à leitura; criação de grupos de apoio entre parlamentares e formadores de opinião (BRASIL, 2010).

Esse primeiro bloco de ações se dedica à valorização institucional da leitura e do livro no âmbito das esferas governamentais, especialmente, estimulando a criação de marcos legais, inclusive por meio de articulação com parlamentares, e instâncias de proposição e acompanhamento dos programas públicos para a área. Ainda, à inserção do tema "livro e leitura" na pauta de pesquisas acadêmicas, por meio de seminários, congressos etc., e ao estímulo para a criação de fundos para o financiamento de projetos para a promoção da leitura.

Apesar da intenção de valorizar institucionalmente a leitura, podemos afirmar que as ações listadas se referem mais à criação e à implementação de um lugar institucional do que de valorização, propriamente dita. Entendemos que a abertura desses espaços e articulações passa pela valoração simbólica da leitura e do livro e pelo reconhecimento de sua importância. Em outras palavras, é necessário que a leitura se torne um bem, algo importante, compreendido como necessário à formação das pessoas, para que ela se torne tema de pesquisas, seminários e congressos ou objeto de planos e políticas públicas.

O segundo ponto do eixo 3 diz respeito às "ações para criar consciência sobre o valor social do livro e da leitura" e tem como desdobramento a realização de campanhas institucionais, inclusive com depoimentos de formadores de opinião sobre sua experiência com livro e leitura, em jornal, televisão, rádio, revistas, outdoors, cinema e outras mídias para a valorização da leitura, do livro, da literatura e das bibliotecas; publicações de histórias de leitura e dicas de personalidades e pessoas anônimas sobre livros, além de campanhas para a conscientização sobre a importância da biblioteca pública.

Para a análise do segundo ponto, tomaremos como ponto de partida o entendimento de Adorno (1995) para a consciência, isto é, “[...] o pensar em 
relação à realidade, ao conteúdo - a relação entre as formas e as estruturas de pensamento do sujeito e aquilo que este não é." (ADORNO, 1995, p. 151). Sob essa ótica, a realização de campanhas, principal recomendação do PNLL (dentre os quatro itens propostos neste ponto, três são campanhas), parece na contramão.

De acordo com Lajolo e Zilberman (2009), as campanhas partem do pressuposto de que a população brasileira lê mal e pouco por não ter consciência do valor da leitura, não em função de um sistema de ensino complexamente ineficiente em sua tarefa de ensinar a ler e a escrever. Dessa maneira, as campanhas teriam como missão preencher essa lacuna, convencendo as pessoas de que ler é muito importante, assim como faz em outras áreas, como o meioambiente e a saúde, por exemplo.

Nessa perspectiva, a leitura é transformada em uma mercadoria, a ser adquirida sem a consciência de que nos fala Adorno, a saber, o pensar em relação ao conteúdo e sua relação com o próprio sujeito:

O ponto de partida (e de chegada também?) é um produto a ser vendido, não importando - para a venda - suas características e especificidade; a estratégia, por sua vez, é paternalista, mesmo quando as causas são legítimas e apresentam grande relevância, como é o caso da leitura. (LAJOLO; ZILBERMAN, 2009, p. 128).

Dito de outra maneira, as pessoas passariam a ler porque as campanhas disseram, sem explicar por que, que isso é importante, assim como fazem com outros "produtos". A importância da leitura e do livro, que passa a fazer parte dos discursos do senso-comum, é oferecida e recebida pela maioria, acriticamente, como uma mercadoria ao alcance de qualquer pessoa, transferindo, desse modo, a responsabilidade pela participação na cultura escrita para o indivíduo, que escolhe ler ou não ler, agora que foi alertado e está consciente da questão.

Na mesma direção aponta Castrillón (2011), que entende que as campanhas para a promoção da leitura, realizadas no mundo inteiro há três ou quatro décadas, desviam a nossa atenção do verdadeiro problema. Para ela, 
em conta que nada se torna necessário - e muito menos a leitura, que é um exercício difícil, que exige um tempo cada vez mais escasso e um esforço que poucos estão dispostos a realizar - se não se tiver a íntima convicção de que ler pode ser um meio para melhorar as condições de vida e as possibilidades de ser, de estar e de atuar no mundo. (CASTRILLÓN, 2011, p. 20).

Como Lajolo e Zilberman (2009), Castrillón (2011) denuncia a intenção de convencimento das campanhas, que tentam oferecer a leitura para a população, sem contribuir para o entendimento da leitura e da escrita como práticas históricas, sociais, culturais e econômicas, cuja participação determina, em grande medida, as condições objetivas e subjetivas das pessoas.

A compreensão da leitura como algo que possa ser valorizado simbolicamente através de campanhas para a "criação de consciência", sem a exposição das condições que nos levam, aos brasileiros e à população de baixa renda no mundo todo, de maneira geral, a ler pouco e mal, revela um entendimento restrito e ingênuo sobre a questão. Isso porque concebe a leitura, e a educação, em grande medida, como algo isolado em si mesmo, uma vez que não considera as condições objetivas e subjetivas para sua aprendizagem e apropriação. Como afirma Britto (2003) ao analisar alguns projetos para a promoção da leitura ${ }^{4}$,

[...] criam-se em torno desta ideia correntes de leitores e movimentos de promoção da leitura muito semelhantes aos grupos de proselitismo religioso e de ação beneficente e organizam-se campanhas à maneira de clubes de assistência e de filantropia, para levar leitura aos presídios, hospitais, parques, favelas, etc., para que todos fiquem melhores. Tais ações têm evidentes implicações políticas e éticas, representando não apenas uma concepção de leitura, de ensino da leitura ou de promoção da leitura, mas e principalmente uma concepção de sociedade, em que se sobressai a mensagem de que é possível incluir toda a gente sem modificar o modelo excludente de sociedade. (BRITTO, 2003, p. 140).

O autor reforça a denúncia à criação e à repetição de um discurso que fazem da leitura uma mercadoria, um bem em si mesmo, desconsiderando suas condições de realização. Mais que isso, a uma ordem social que privilegia e reproduz esse entendimento, na medida em que, à maneira dos discursos proselitistas, oferecem livros como algo "para que todos fiquem melhores". 
Ainda no segundo ponto do eixo 3, o PNLL recomenda a publicação de testemunhos e histórias de leitura de personalidades e pessoas anônimas. Os depoimentos parecem ter como objetivo a sensibilização das pessoas, por meio de sua admiração pela personalidade, no primeiro caso, ou de sua identificação com alguém anônimo, no segundo, dos benefícios da leitura.

Em algumas situações, os testemunhos, como são chamados pelo PNLL, podem cumprir um importante papel, se disserem de como a leitura contribuiu, na vida de quem faz o relato ou na experiência relatada, para uma compreensão mais ampliada e diversa do mundo, especialmente se isso foi mediado pela leitura e pela escrita, como no texto do escritor Graciliano Ramos que abre este artigo. Porém, se os depoimentos se pautarem nas personalidades ou em um aspecto messiânico da leitura - a leitura que salva, a leitura maravilhosa, a leitura hedonista -, desconsiderando ou extrapolando seu aspecto essencial, isto é, a compreensão e a participação na cultura escrita, há o risco de, mais uma vez, ela ser oferecida como uma mercadoria, como um produto de marketing qualquer, anunciado por alguém que, naquele momento, atrai a atenção das pessoas.

O terceiro ponto do eixo 3 tem como recomendação "publicações impressas e outras mídias dedicadas à valorização do livro e da leitura" e destaca a publicação de livros, cadernos, suplementos especiais, jornais, revistas, páginas eletrônicas sobre leitura, literatura, livro e bibliotecas, além da realização de programas permanentes e especiais sobre o tema na televisão e no rádio.

Diferentes das campanhas, previstas no segundo ponto do eixo 3, que impõem a leitura como algo de cuja importância a população precisa ser convencida, as recomendações aqui propostas criam um espaço para tratar, relatar, divulgar e refletir sobre a leitura, a literatura, os livros e as bibliotecas. Dito de outra maneira, inserem o assunto nas notícias diárias, levando os leitores e espectadores de jornais impressos, radiofônicos e televisivos a tomarem conhecimento de avaliações do desempenho de leitura dos brasileiros ou a ouvirem, lerem, assistirem a uma entrevista com um escritor, por exemplo. No âmbito acadêmico, abrem possibilidades de divulgação de pesquisas sobre a 
escrita de um determinado autor, sobre a avaliação de políticas públicas para a área ou a experiência de leitura na primeira infância, por exemplo, oferecendo sustentação teórica para o desenvolvimento de projetos e para a qualificação de práticas docentes e bibliotecárias, além de provocar e estimular novas indagações, novos problemas de pesquisa. Em resumo, a publicação e a veiculação de matérias ou programas sobre a leitura, a literatura, o livro e as bibliotecas fazem o assunto circular, chamando a atenção da população para a questão e promovendo a produção de mais relatos e conhecimento sobre o tema.

\section{Considerações finais}

O PNLL foi construído coletivamente por representantes do poder público e da sociedade civil em reuniões, seminários, conferências setoriais e audiências públicas realizadas no Distrito Federal e em todos os estados do país, envolvendo instituições e pessoas dos mais diversos segmentos da área, como leitores, professores, bibliotecários, mediadores de leitura, servidores públicos, agentes comunitários, escritores, ilustradores, tradutores, editores, livreiros e artistas, dentre outros. Em um exercício de participação social democrática, acolheu e ocupou-se dos mais diversos interesses, demandas e proposições, tornando-se um documento representativo do que poder público e sociedade civil entendem serem as prioridades e desafios para a democratização do acesso à leitura e à escrita no Brasil.

A criação de um eixo para a valorização institucional da leitura e incremento de seu valor simbólico obedece a essa lógica, dizendo do que os muitos participantes da elaboração do PNLL naquele momento consideraram importante como recomendação para projetos e programas, públicos e privados, na área. No entanto, passados seis anos de sua primeira revisão, realizada em conferências setoriais por todo o país em 2009 e finalizada em 2010, durante a Conferência Nacional de Cultura, em Brasília, faz-se necessária uma reflexão sobre alguns pontos do eixo 3 .

Para que o valor simbólico construído para a leitura não se torne uma violência simbólica, compreendida por Bourdieu (2010) como a imposição velada de uma visão de mundo, sob a aparência de normalidade, que garante a 
relação de dominação a alguns grupos, como no que está subjacente às campanhas propostas, é importante que a concepção da leitura e, naturalmente, do seu valor simbólico no âmbito do PNLL sejam constantemente discutidos e ressignificados, uma vez que esse entendimento norteará muitas das ações do Plano.

Sendo o PNLL um documento assinado pelos ministérios da Cultura e da Educação, ele carrega em si a legitimidade do discurso oficial e da ordenação das ações para a democratização do acesso à leitura e à escrita, especialmente nas instituições, programas e editais públicos. Assim, tem um lugar de enunciação privilegiado e, para muitos, inquestionável. Para o seu fortalecimento como um instrumento democrático de participação social, é importante que o PNLL revisite seus conceitos e faça ajustes em seus eixos de ação, visando uma perspectiva de leitura que contribua para o desenvolvimento humano e para a formação de consciência, como postula Adorno (1995). Ou, nas palavras de Graciliano Ramos, para a adivinhação das inúmeras páginas abertas no mundo, acessíveis a quem junta as letras e forma as palavras.

\section{Referências}

ADORNO, Theodor W. Educação e emancipação. Rio de Janeiro: Paz e Terra, 1995.

BOURDIEU, Pierre. O poder simbólico. Rio de Janeiro: Bertrand Brasil, 2010.

BOURDIEU, Pierre; CHARTIER, Roger. A leitura: uma prática cultural. Debate entre Pierre Bourdieu e Roger Chartier. In: CHARTIER, Roger (Org.).

Práticas de Leitura. São Paulo: Estação Liberdade, 2011.

BRASIL. Ministério da Educação. Ministério da Cultura. Plano Nacional do Livro e Leitura - PNLL. Brasília, DF, 2010.

BRITTO, Luiz Percival Leme. Contra o consenso: cultura escrita, educação e participação. Campinas, SP: Mercado de Letras, 2003.

CASTRILLÓN, Silvia. O direito de ler e de escrever. São Paulo: Pulo do Gato, 2011. 
COUTINHO, Carlos Nelson (Org.). O leitor de Gramsci: escritos escolhidos. Rio de Janeiro: Civilização Brasileira, 2011.

LAJOLO, Marisa; ZILBERMAN, Regina. Das tábuas da lei à tela do computador: a leitura em seus discursos. São Paulo: Ática, 2009.

RAMOS, Graciliano. Infância. Rio de Janeiro: Record, 1986.

\title{
Symbolic value of reading at National Plan of Book and Reading: an analysis
}

\begin{abstract}
This paper presents and discusses the proposals of the National Plan of Book and Reading - PNLL to value reading as a cultural asset in its action axis number three, entitled "Institutional Enhancement of reading and increase of its symbolic value," in the light of Pierre Bourdieu's concept of "symbolic violence". It concludes that the concepts of reading and, of course, of its symbolic value in the context of PNLL must be constantly discussed and reevaluated, since this understanding will guide many of the actions of the Plan.
\end{abstract}

Keywords: Reading. Symbolic value. Public policies. PNLL.

Recebido em: 31/10/2016

Aceito em: 06/01/2017

${ }^{1}$ Devido ao grande aumento de projetos e iniciativas para a promoção da leitura nos últimos anos, houve também um crescimento significativo dos profissionais que trabalham com a formação de leitores. A esses profissionais, independente de sua formação, dá se o nome de mediadores de leitura.

${ }^{2}$ Dados da pesquisa "Produção e vendas do setor editorial brasileiros", realizada pela Câmara Brasileira do Livro (CBL), Sindicato Nacional dos Editores de Livros (SNEL) e Fundação Instituto de Pesquisas Econômicas (FIPE). Desse total, 49,10\% são livros didáticos.

${ }^{3}$ BRASIL. Ministério da Cultura. Ministério da Educação. Guia para elaboração e implantação dos planos estadual e municipal do livro e da leitura. Brasília, [2010?].

${ }^{4}$ Aqui o autor se dedica a uma análise da Expedição Vaga-Lume, projeto que então tinha como objeto a implantação de bibliotecas em comunidades ribeirinhas da Amazônia. 